\title{
CONTRIBUIÇÕES DO USO DAS TECNOLOGIAS NA EDUCAÇÃO ESPECIAL E INCLUSIVA POR MEIO DO PROGRAMA INSTITUCIONAL DE BOLSAS DE INICIAÇÃO À DOCÊNCIA (PIBID)
}

Eliane Regina Moreno Falconi ${ }^{1}$, Matheus Augusto Mendes Amparo ${ }^{2}$, Danielle Aparecida do Nascimento dos Santos ${ }^{3}$, Elisa Tomoe Moriya Schlünzen ${ }^{4}$

\footnotetext{
${ }^{1}$ Secretaria Municipal de Educação. Especialista do Atendimento Educacional Especializado, Presidente Prudente - SP. ${ }^{2}$ Universidade Estadual Paulista - UNESP. Mestrado em Educação, Presidente Prudente - SP. ${ }^{3}$ Universidade Estadual Paulista - UNESP. Doutorado em Educação, Presidente Prudente - SP. ${ }^{4}$ Universidade Estadual Paulista - UNESP. Docente, Presidente Prudente - SP.
}

\section{RESUMO}

O PIBID é desenvolvido no âmbito da Coordenação de Aperfeiçoamento de Pessoa de Nível Superior (Capes) em parceria com as Instituições de Ensino Superior e tem por objetivo a valorização da formação de professores para a educação básica. Sendo assim, 15 bolsistas passaram a realizar nas escolas públicas municipais um atendimento aos estudantes com deficiências, transtornos globais do desenvolvimento e transtornos do espectro autista Até o momento o subprojeto tem possibilitado a criação de estratégias de ensino usando Objetos Educacionais e TDIC que são usadas para que os bolsistas colaborem para o desenvolvimento da aprendizagem dos EPAEE presentes nas salas, bem como tem se observado o grande intercâmbio entre os envolvidos. Diante dessas premissas, neste artigo serão apresentadas os pressupostos teóricos utilizados e as estratégias construídas, tal como as contribuições do programa para a produção de conhecimento em Educação Especial e Inclusiva.

Palavras-chave: PIBID, Estudantes Público Alvo da Educação Especial, Tecnologias Digitais de Informação e Comunicação.

\section{CONTRIBUTION OF THE USE OF TECHNOLOGY IN SPECIAL EDUCATION AND INCLUSIVE FOR INSTITUTIONAL PROGRAM OF THE TEACHING INITIATION (PIBID)}

\begin{abstract}
The PIBID is developed within the Coordenação de Aperfeiçoamento de Guy de Nível Superior (Capes) in partnership with higher education institutions and aims at the enhancement of teacher education to basic education. Thus, 15 scholars began to perform in public schools a municipal service to students with disabilities, global development disorders and autistic spectrum disorders by the time the subproject has made possible the creation of teaching strategies using educational and TDIC Objects that are used so that the fellows collaborate learning development of EPAEE present in the roomsas has been noted the great exchange between those involved. Given these premises, this article will be presented the theoretical assumptions used and built strategies, such as the contributions of the program to the production of knowledge in Special and inclusive Education.
\end{abstract}

Keywords: PIBID, Target group of special education students, Digital information and Communication Technologies. 


\section{INTRODUÇÃO}

O Programa Institucional de Bolsa de Iniciação à Docência (PIBID), teve como cerne o Plano de Desenvolvimento da Educação de 2007 (PDE), que buscava estratégias para uma melhor formação e valorização dos professores, sendo proposto a partir de 2008, pela Coordenação de Aperfeiçoamento de Pessoal de Nível Superior (Capes), fundação vinculada ao MEC. De acordo com dados gerais do programa, o PIBID visa estabelecer uma relação mútua entre a educação superior e a educação básica.

Para isso o programa divulga editais por meio do Portal da CAPES, onde as Instituições de Ensino Superior (IES) que possuam cursos de licenciatura e que estejam interessadas, possam enviar propostas de projetos que contemplem uma ou diversas áreas do conhecimento.

Portanto, por intermédio dos projetos elaborados pelas IES os estudantes de cursos na área das Licenciaturas são selecionados por critérios definidos em cada IES recebem uma bolsa de iniciação à docência para que 'se dediquem ao estágio nas escolas públicas e que se comprometam com o exercício do magistério na rede pública, uma vez graduados' (BRASIL, 2007, p. 17).

Os estudantes bolsistas são imersos no cotidiano escolar antes de completar a sua formação inicial, criando assim um vínculo com a escola. Desse modo, tem a oportunidade de não só vivenciar a experiência da docência, mas também podem contribuir com os docentes em exercício na execução de diferentes atividades de ensino, voltadas a temáticas específicas, garantindo a aplicabilidade do que aprendem no contexto da sua formação.

Os editais PIBID oferecem a oportunidade de execução de projetos que contemplam todas as áreas de licenciatura como: Pedagogia, Matemática, Ciências, Química, Física e outras. Ao mesmo tempo, há a possibilidade de que os projetos tenham subprojetos, que contemplem áreas específicas do conhecimento, como por exemplo, em Pedagogia: Alfabetização, Artes, Educação Especial, Avaliação, entre outras.

Nessa perspectiva, o projeto proposto pelo curso de Licenciatura em Pedagogia da Faculdade de Ciências e Tecnologia (FCT/UNESP), campus de Presidente Prudente/SP com base no edital PIBID - CAPES 11/2012 foi aprovado, tendo como perspectiva a execução de três subprojetos, que contemplam os seguintes eixos temáticos:

1) Alfabetização em uma perspectiva sociolinguística;

2) Educação de Jovens e Adultos;

3) O uso de Tecnologias Digitais de Informação e Comunicação (TDIC) como recursos para a aprendizagem de Estudantes Público-Alvo da Educação Especial (EPAEE). 
Neste sentido, será abordado de forma específica o terceiro eixo, executado por pesquisadores e estagiários bolsistas vinculados ao Grupo de Pesquisa Ambientes Potencializadores para a Inclusão (API), que integra o Centro de Promoção para Inclusão Digital, Escolar e Social (CPIDES) da unidade. O subprojeto tem como foco o desenvolvimento de práticas docentes para o fortalecimento da aprendizagem dos EPAEE por meio do uso de Objetos Educacionais (OE) e das TDIC, nos anos iniciais.

Diante disto, este artigo pretende apresentar o processo de iniciação a docência de 15 bolsistas, com foco nas atividades realizadas durante o segundo semestre letivo do ano de 2012 e ano letivo de 2013, com os EPAEES, tal como o resultado das atividades propostas na formação e das atividades realizadas no contexto escolar, no qual já foram identificadas contribuições, aos participantes.

\section{METODOLOGIA}

O trabalho desenvolvido com as 15 estudantes bolsistas no subprojeto durante o ano letivo de 2012 e primeiro semestre de 2013, caracterizado como Fase A, ocorreu em 05 (cinco) unidades escolares do município de Presidente Prudente/SP, atingindo um total de 180 estudantes atendidos, entre estes Estudantes Público alvo da Educação Especial (EPAEE) e estudantes com dificuldades de aprendizagem, sem diagnóstico clínico específico de deficiência. A partir do segundo semestre de 2013, caracterizado como Fase B, o trabalho passou a ser desenvolvido em três das cinco unidades escolares anteriores, contando com o atendimento a 126 estudantes do município.

O trabalho, em um primeiro momento, foi realizado por meio da elaboração de um roteiro por parte das estudantes bolsistas, direcionado à coleta de dados e informações a respeito da unidade escolar. A equipe executora julgou necessário o levantamento dessas informações para o desenvolvimento do decorrer do trabalho de iniciação a docência.

A partir do quadro inicial levantado mediante a aplicação do roteiro, a iniciação a docência foi iniciada nas unidades escolares. Com o conhecimento do diagnóstico da unidade escolar, dos EPAEES, suas salas e período de frequência, fizeram opção para atendimento de acordo com sua disponibilidade de horário, que deveria ser distribuído em 40 horas mensais, contando com reuniões semanais realizadas na Unesp. Para tanto, houve a opção para que o atendimento na escola fosse realizado em um único dia durante o período de 5 (cinco) horas/aula como também em 5 (cinco) horas/aulas divididas em dois dias de atendimento. Todas passaram a desenvolver o atendimento de forma a contemplar, portanto, as cinco horas/aula semanais. 
Para o desenvolvimento das atividades de iniciação à docência foi elaborado um cronograma mensal de atendimento, em parceria com os gestores e professores das unidades escolares. Além disso, esse cronograma foi elaborado pelas estudantes bolsistas junto com uma professora bolsista supervisora do projeto. No cronograma foram consideradas as necessidades e disponibilidades das unidades e das bolsistas.

Para a realização das atividades de iniciação à docência nas unidades escolares, foram realizados estudos, organização e planejamento de propostas de intervenção em função das demandas estabelecidas pelos gestores, professores das unidades escolares.

As atividades desenvolvidas nas unidades escolares foram direcionadas mediante um planejamento que teve como parâmetro a Política Nacional de Educação Especial na Perspectiva da Educação Inclusiva e as características dos EPAEES, não destacando, ou priorizando suas diferenças como ponto negativo, mas considerando as especificidades de cada um. Respeitando e valorizando as diferenças, de forma que as dificuldades fossem minimizadas.

Para tanto, as estudantes bolsistas foram orientadas semanalmente pela professora supervisora, de forma que pudessem "ver" cada estudante atendido em sua individualidade, enxergando o seu potencial e, a partir dos conhecimentos sobre os estudantes, foram orientadas a desenvolver propostas de ensino que colaborassem e auxiliassem no desenvolvimento dos EPAEES.

De acordo com Gatti (2009), a formação deve ser pensada e desenvolvida a partir da abordagem da função social da escola, que é ensinar às novas gerações o conhecimento historicamente construído e consolidar valores e práticas sociais coerentes com a vida, na sociedade da informação e do conhecimento. Nesse sentido, essa perspectiva foi adotada na execução do projeto.

Além disso, segundo Mantoan (2010), nunca é demais lembrar que aprender é uma ação humana criativa, individual heterogênea e regulada pelo sujeito da aprendizagem, independentemente de sua condição intelectual ser mais ou ser menos privilegiada.

Assim, foram propostas diferentes metodologias de ensino usando recursos pedagógicos e Objetos de Aprendizagem visando enriquecer os saberes da escola, ou seja, os conteúdos curriculares. Por isso, foi considerada a diversidade, que deriva das formas singulares de nos adaptarmos cognitivamente a um dado conteúdo, a uma situação problema, a um novo tema de estudo. Ensinar, por sua vez, passou a ser um ato coletivo. Durante a primeira fase de desenvolvimento do projeto, em duas das unidades escolares municipais, houve a solicitação para que as discentes bolsistas realizassem um atendimento de intervenção direcionado aos estudantes 
com dificuldades de aprendizagem. Os estudantes atendidos nessa etapa ainda não possuíam avaliação multidisciplinar e diagnóstico clínico, mas, de acordo com diagnóstico pedagógico apresentavam dificuldades acentuadas de aprendizagem. Como aguardavam ou estavam em processo de avaliação, no desenvolvimento do projeto, o auxílio e colaboração das discentes bolsistas foi uma opção dos gestores escolares. Completando as atividades de formação das estudantes bolsistas, haviam ainda encontros quinzenais do grupo de pesquisa API, em que esses temas eram aprofundados por pesquisadores e profissionais da área.

Nos encontros houveram momentos de dinâmicas, atividades práticas (oficinas e confecção de materiais) e orientações. Os encontros sempre eram seguidos de estudos não presenciais, no sentido de reforçar as atividades realizadas presencialmente.

Dentre os estudos e práticas realizadas, destacamos:

- A reflexão e estudo sobre a Política Nacional de Educação Especial na Perspectiva da Educação Inclusiva;

- Organização de pastas (portfólios), e caderno de registros sobre os estudos realizados com a professora supervisora e para registro das atividades de iniciação a docência realizadas nas unidades escolares;

- Elaboração de relatórios semanais sobre as atividades realizadas;

- Pesquisa de Objetos Educacionais do Banco Internacional de Objetos Educacionais voltados à alfabetização e EPAEE e de estudantes com dificuldades de aprendizagem (nomes, temas, conteúdos, sobre o que tratam, forma de desenvolvimento (interativo ou explicativo);

- Elaboração de pautas Relato sobre Aspectos importantes a serem observados em relação ao EPAEE e sua participação em sala de aula e ambiente escolar;

- Avaliação das atividades desenvolvidas por meio do retorno das bolsistas através do envio de suas pesquisas, do interesse no tema, da participação quanto a sugestões e questionamentos; e estudo sobre material do MEC: A Escola Comum Inclusiva; O AEE para alunos com Deficiência Intelectual; O AEE para alunos com Deficiências Múltiplas; Transtornos Globais do Desenvolvimento; Recursos Pedagógicos Acessíveis e Comunicação Aumentativa e Alternativa; (em estudo); Orientação e Mobilidade, Adequação Postural e Acessibilidade Postural / Livro Acessível e Informática Acessível; (em estudo). 


\section{RESULTADOS}

As experiências vivenciadas têm demonstrado o quanto é importante essa iniciativa de iniciação a docência para atuar com crianças com deficiências. Além disso, na troca de experiências com os professores das unidades escolares as bolsistas têm descoberto que trabalhar com esse público exige tempo, atenção diferenciada e desenvolvimento de estratégias de ensino diversificadas para que sejam alfabetizadas. Tem elaborado artigos científicos com a fundamentação teórica e relato das experiências construídas, conforme anexo.

Nesse período foram organizados, produzidos e desenvolvidos estudos diversos e materiais pedagógicos foram confeccionados para serem utilizados como recursos de ensino nos atendimentos aos EPAEE ou estudantes com dificuldades de aprendizagem nas unidades escolares. Dentre os materiais confeccionados se destacam os Jogos Pedagógicos de alfabetização, que serviram para uma participação mais efetiva dos estudantes no contexto escolar. 0 jogo permite ao estudante explorar, praticar e compreender melhor seu processo de aprendizagem. Além disso, diminui barreiras e estimula maior participação, cooperação e desenvolvimento global do estudante.

Além disso, o uso de Objetos Educacionais tem contribuído para o avanço dos estudantes quanto sua participação e desenvolvimento da aprendizagem. Deste modo, estamos propondo estratégias através do uso de Tecnologias Digitais de Informação e Comunicação (TDIC) para atender os EPAEES contribuindo efetivamente com seu desenvolvimento e aprendizagem no ambiente escolar.

Por fim, os impactos observados no subprojeto até o momento, se da através da observação das estratégias de ensino adotadas pelas bolsistas para um melhor e maior conhecimento das práticas educacionais desenvolvidas e utilizadas nas unidades escolares com os EPAEES. Os professores que recebem as bolsistas na unidade escolar tem a oportunidade de ter auxílio e colaboração no uso de tecnologias e elaboração de atividades para o atendimento dos seus alunos. Esta troca de experiências tem enriquecido muito o programa, no sentido da construção de conhecimentos na área, bem como contribuído para fortalecimento da parceria entre universidade e escolas públicas municipais.

\section{DISCUSSÃO}

No decorrer do período de desenvolvimento, as discentes bolsistas tiveram a oportunidade de participar de Congressos, Seminários e Encontros de Educação, apresentando relatos de suas 
experiências e vivências de iniciação a docência. O compartilhamento dessas experiências foi também muito importante para a sua formação acadêmica profissional.

Assim, o conjunto das experiências de iniciação a docência vivenciadas pelas discentes bolsistas foram resultados importantes para sua formação acadêmica. Todas as atividades empenhadas contribuíram para a construção dos seus conhecimentos acadêmicos e práticos, propiciando uma interlocução entre o que aprendiam na universidade, com o que aprendiam na unidade escolar.

Além disso, as discentes bolsistas tiveram a oportunidade de vivenciar e participar mais efetivamente do trabalho pedagógico realizado em uma unidade escolar, conhecendo as especificidades do processo de inclusão escolar e desenvolvendo na prática propostas de ensino para intervenção na aprendizagem de EPAEE.

Por outro lado, os professores que receberam as discentes bolsistas nas unidades escolares tiveram a oportunidade de obter dicas e auxílios para o uso de tecnologias, quando possível, e para a elaboração de atividades para um atendimento específico aos seus estudantes. Essa troca de experiências foi enriquecida pela experiência dedicada ao projeto por parte da professora supervisora, que contribuiu para o desenvolvimento de diferentes estratégias para a área da Educação Especial.

\section{CONCLUSÃO}

Verificamos que o programa permitiu que houvesse um real trabalho de parceria, onde a professora supervisora, que é professora especialista e atua no Atendimento Educacional Especializado da rede pública municipal, auxiliasse as discentes bolsistas na complementação de sua formação, que consequentemente auxiliaram os professores das unidades escolares, e o processo inverso também ocorreu. Assim, o projeto também favoreceu a construção de um conhecimento real, por parte das discentes bolsistas, sobre as principais características dos EPAEE matriculados e frequentes na rede regular de ensino, pensando e elaborando estratégias para o desenvolvimento de sua aprendizagem.

Nesse sentido atendemos aos pressupostos da política, avaliando pedagogicamente as estratégias propostas em um processo dinâmico, considerando os conhecimentos prévios dos professores nas unidades escolares e os conhecimentos das discentes bolsistas, configurando uma ação pedagógica processual e formativa.

Para tanto, todas as estratégias criadas, desde a intervenção individual até o trabalho realizado no laboratório de informática foram considerados como práticas inovadoras e 
diferenciadas, que incentivaram o aprimoramento de habilidades por parte de todos os participantes.

Sendo assim, a parceria entre o programa e as unidades escolares fortaleceu a formação inicial das discentes bolsistas, mas também a formação continuada e em serviço da professora supervisora e dos professores das unidades escolares. Esse relacionamento entre universidade e professores da rede regular municipal teve como eixo norteador o objetivo do PIBID, de inserir os licenciandos no cotidiano escolar, onde puderam criar estratégias de ensino, aprender na ação e participar de experiências metodológicas, tecnológicas e práticas, em uma abordagem multi e interdisciplinar. Essas estratégias conjuntas contribuíram também para a identificação de problemas de ensino e de aprendizagem, e atuação com foco nos conhecimentos da Educação Especial, usando recursos tecnológicos.

\section{REFERÊNCIAS}

BRASIL. Ministério da Educação. O Plano de Desenvolvimento da Educação: razões, princípios e programas. Brasília, DF: MEC, 2007.

FIGUEIREDO, R. V. Escola de atenção às diferenças. Programa Salto para o futuro. Ano XX, Boletim 03, abril, 2010.

GATTI, B.A. et al. Formação de professores para o ensino fundamental: instituições formadoras e seus currículos; relatório de pesquisa. São Paulo: Fundação Carlos Chagas; Fundação Vitor Civita, 2008. $2 v$.

GATTI, Bernardete; BARRETTO, Elba Siqueira de Sá. Professores no Brasil: impasses e desafios. Brasília: Unesco, 2009.

MANTOAN, M. T. E. O direito à diferença nas escolas - questões sobre a inclusão escolar de pessoas com e sem deficiências. Revista Educação Especial. Edição 2004, no 23. 2010 .

MENDONÇA, Rosa Helena. Coordenação Pedagógica em Foco. Salto para o Futuro/TV ESCOLA (MEC), 2010.

PAREDES, G. G. O. Um estudo sobre o PIBID: saberes em construção na formação de professores de Ciências. 2012. 171 f. Dissertação (Mestrado) - Programa de Pós-Graduaão em Educação em Ciências e Matemática, Universidade Federal do Paraná, Curitiba, 2012. 